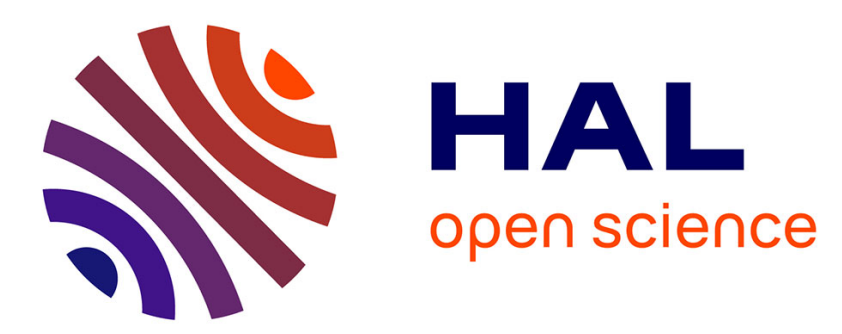

\title{
RobAFIS student competition actuality: A continuously evolving pedagogy for Systems Engineering Jean-Claude Tucoulou, David Gouyon
}

\section{To cite this version:}

Jean-Claude Tucoulou, David Gouyon. RobAFIS student competition actuality: A continuously evolving pedagogy for Systems Engineering. INSIGHT - International Council on Systems Engineering (INCOSE), 2015, AFIS Doctoral Symposium: Advancing Systems Analytics and Modeling in French Universities, 18 (4), pp.12-13. hal-01250742

\section{HAL Id: hal-01250742 \\ https://hal.science/hal-01250742}

Submitted on 5 Jan 2016

HAL is a multi-disciplinary open access archive for the deposit and dissemination of scientific research documents, whether they are published or not. The documents may come from teaching and research institutions in France or abroad, or from public or private research centers.
L'archive ouverte pluridisciplinaire HAL, est destinée au dépôt et à la diffusion de documents scientifiques de niveau recherche, publiés ou non, émanant des établissements d'enseignement et de recherche français ou étrangers, des laboratoires publics ou privés. 


\title{
RobAFIS student competition actuality:
}

\section{A continuously evolving pedagogy for Systems Engineering}

\author{
Jean-Claude Tucoulou (jeanclaude.tucoulou@incose.org) \& David Gouyon \\ (david.gouyon@incose.org)
}

This paper presents the RobAFIS competition which is yearly organized since 2006, by AFIS, the French chapter of INCOSE. This competition, as well as its pedagogical objectives, have been presented in previous editions on Insight [1] [2].

RobAFIS enhances AFIS action, offering educational and research institutions an operation to better understand and develop the use of systems engineering best practices, as recommended and formalized by AFIS and more recently by GRCSE [3]. The recommended reference document for RobAFIS is the book "To discover and understand Systems Engineering"[4].

Since 2007, the RobAFIS competition repositories and development files provided by teams are available as examples in the member area of the AFIS web site [5], in order to be viewed and analyzed by the students and teachers.

Students and their supervising teachers have the opportunity to exchange with the jury AFIS expert members, working in industry or teaching Systems Engineering. During development, these experts answer, via a FAQ page on a RobAFIS dedicated collaborative space [6], questions about technical or methodological issues related to stakeholder requirements or to the development document.

The main objective of RobAFIS is to highlight the benefits of basing systems engineering education on a project life cycle realization: a full life cycle including the implementation of an operational system, deployed by a client, in a real environment.

\section{2015: "10th anniversary special edition"}

Each year this project benefits from previous edition feedback, in order to continuously improve the educational value of the event. Systems engineering best practices are also those on which AFIS technical committees have worked in last years, to ensure that companies can improve their methods, and more generally to progress on the engineering of the product and services they develop.

This competition is open to bachelor or master degrees students, in a systems engineering discipline. Since the beginning of RobAFIS in 2006, about twenty five different institutions participated at least one time, with an average of twelve registered teams each year.

To celebrate the $10^{\text {th }}$ anniversary of RobAfis, we invite the maximum of participating teams since 2006, while inviting new teams to participate.

\section{Recent technical subjects:}

\section{a. 2014: product lines and remotely operable systems problematics}

The specification of 2014 system was based on the design and assembly of 3 configurations, able to ensure 3 different object transport scenarios. Each configuration had to be composed of a common platform and a modular subsystem adapted to scenario features.

The main objective was first to highlight the importance of functional and physical architectures study phase, of optimization and justification of the selected architecture, and then to apprehend the concepts of integrated or modular (open) solutions specific to product line variants architecture.

With the introduction of two operating mode during mission progress (automatic mode and remote operated mode), the problem of human introduction during operation was posed. During the final phase, two ergonomics experts were involved during the configuration audit and the operational phase. They assessed the consideration of human factors in engineering and the usability of the HMI, and exchanged with students and teachers on this topic.

\section{b. 2015: Interactions between operators and technical systems}

The objective in 2015 is to highlight the consideration of human factors in systems engineering. This results in the choice of a subject in which the system in operational configuration includes a team of two 
operators working together. Operators interact with the robot and the objects of the deployment environment. This year, only one configuration must be designed, but with a system of interest including the robot, two operators, the burdens to be moved, and the platform on which operates the mobile robot.

Given the major role played by the human factor in the implementation of the system, the ergonomics experts intervene during the final phase to assess the quality of operators HMI and to make immediate feedback to participants.

\section{Introduction of a development in two phases}

To enhance the distinction between system architectural choices and technology choices, in 2015 we proposed a model of development in two phases:

- $\quad$ Phase 1: an upstream study phase, with the supply of a preliminary development document ( $(4)$, focusing on the identification of possible solutions (at least 3 candidate solutions) and on the justified choice of the selected solution, on the basis of studied solutions drafts;

- $\quad$ Phase 2: a full development phase, with the supply of a detailed development document (\$5) and an operational prototype, corresponding to the solution selected in the first phase.

In order to differentiate the sequencing of these two phases and the absence of iteration between phases 1 and 2, phase 1 documents will be provided two weeks before phase 2 documents. The aim is to highlight the specific nature and contribution of both phases, in terms of progressive definition, the first one corresponding mainly to a system vision, the second one to a more product oriented vision.

The scoring scale of development documents and their deliverables has been elaborated in order to highlight the respective issues attached to their good achievement and their contributions to engineering and product overall quality.

\section{Preliminary development document architecture [7]}

At the end of phase 1, student teams have to supply a preliminary development document, structured into 3 deliverables (more details on www.robafis.fr):

1. Preliminary version of requirement referential (Deliverable 10)

2. Presentation of possible architectural designs (Deliverable 20)

3. Justification of architecture choice (Deliverable 40)

\section{Development Document Architecture [7]}

The results of the full development phase 2 are supplied under the form of a detailed development document, structured into 8 deliverables (more details on www.robafis.fr):

1. Final requirement referential (Deliverable 10)

2. Final architectural design (Deliverable 20)

3. Reference configuration (Deliverable 30)

4. Justification of definition (Deliverable 40)

5. Integration, Verification, Validation Plan (Deliverable 50)

6. Maintainability study and maintenance definition (Deliverable 60)

7. Project management (Deliverable 70)

8. Assembly and verification instructions (Deliverable 80) 


\section{Best practices for engineering quality}

With ten years of existence, the RobAfis competition put in evidence various best practices:

- R1: The analysis of the operational environment and the related systems, source of requirements and constraints complementary to those included in the initial functional specifications.

- R2: The study of the functional architecture, an essential step for the requirement analysis and the physical architecture definition.

- R3: The search for candidate architectures and the justified choice of the selected one.

- R4: Performance allocation to functions, subsystems and elementary components, with values and tolerances including component characteristic dispersions.

- R5: A comprehensive requirement repository applicable to the system and its constituents, enriched by requirements identified during the design and applicable to the higher and system levels.

- R6: The realization of a robust solution incorporating functioning margins able to absorb dispersions related to specific constituents or resulting from the integration.

- R7: A justification guaranteeing the ability to achieve the mission, for all scenarios and for implementation boundary conditions.

- R8: The integration of the support system engineering in the system-of-interest engineering.

- R9: The integration of human factors in systems engineering and in operating systems.

- R10: The importance of a preliminary development phase before the full development phase.

\section{ILLUSTRATIONS}

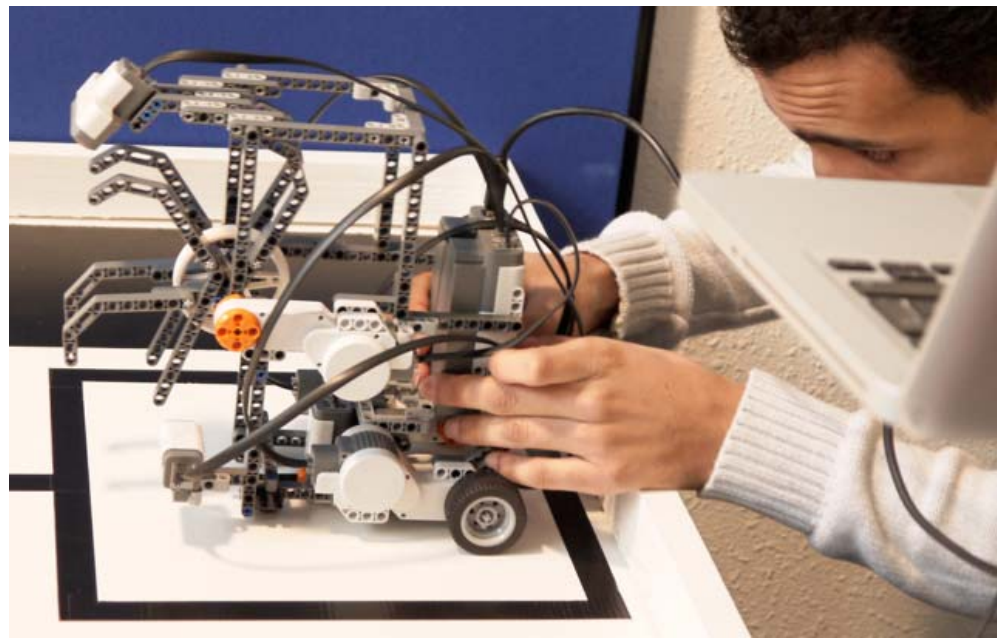

Figure 1: Engineering phase (test)

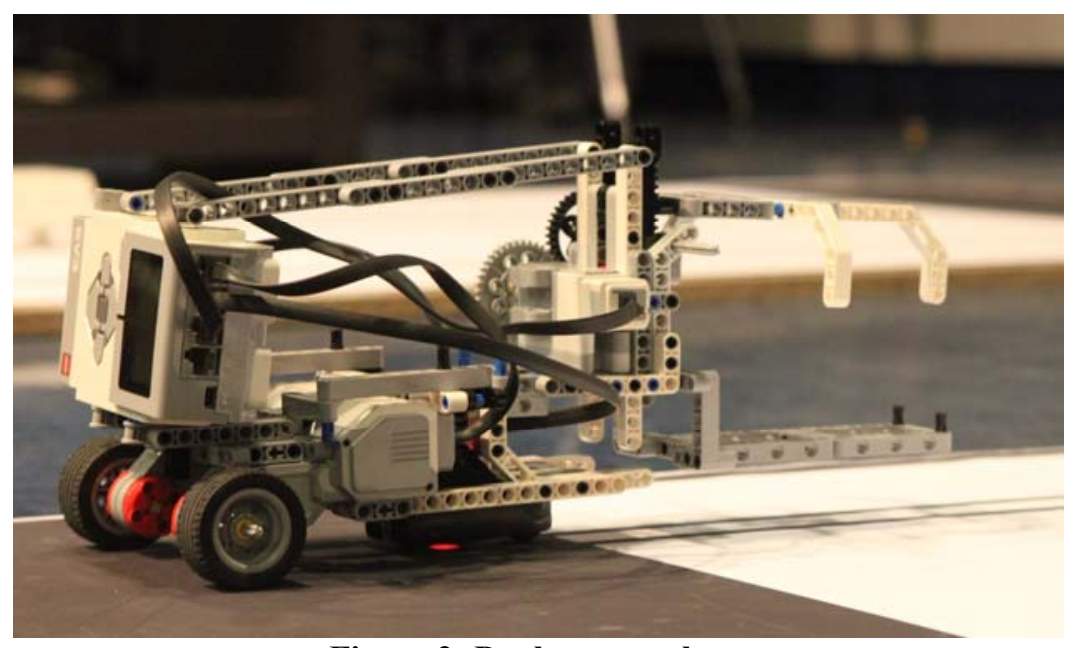

Figure 2: Deployment phase 


\section{Cooperation with GfSE: RobSE 2015.}

For some years, the RobAfis project is presented and discussed at an international level, during INCOSE IW and IS [8] [9], INCOSE EMEA, and within collaboration with other local chapters. In this context, the GfSE, the German chapter of INCOSE, has been in contact with the AFIS since 2014. The first edition of RobSE, a student competition corresponding to RobAfis, will be organized by the GfSE (Mr. Schulze and Ms. Schlüter) with the support of INVENSITY GmbH, Corporate member of the GfSE (Mr. Martinez and Mr. Zutter) and the aid of the AFIS and of Jean-Claude Tucoulou RobAFIS Team Leader.

The event organization followed a visit of the GfSE in France for the 2014 RobAFIS event. This visit confirming the strong interest of the GfSE, it was decided to try to duplicate the concept in Germany. The 2015 RobSE event will be based on a subject kindly provided by the AFIS. This reflect our desire to grow together this interesting event to what could be an international INCOSE event in the future and we are looking forward to this cooperation.

At the moment we write those lines, 3 teams are registered from 2 universities (HOCHSCHULE PFORZHEIM and HOCHSCHULE ESSLINGEN). With 2 registered teams, the Hochschule Pforzheim will host the event the 17 and 18th of December 2015.

\section{References}

[1] Tucoulou, J. C., Gouyon, D., \& Bonjour, E., 2011. A student challenge in systems engineering: RobAFIS 2010. Insight Journal of INCOSE, 14(4), 9-11.

[2] Tucoulou, J. C., \& Gouyon, D., 2013. RobAFIS student competition: from systems engineering to the engineering of one system. Insight Journal of INCOSE, 16(4), 7-10.

[3] Pyster, A., D.H. Olwell, T.L.J. Ferris, N. Hutchison, S. Enck, J. Anthony, D. Henry, and A. Squires (eds.). 2012. Graduate Reference Curriculum for Systems Engineering (GRCSE®). Hoboken, NJ, USA: The Trustees of the Stevens Institute of Technology. Available at: www.bkcase.org/grcse/.

[4] Fiorèse S. and Meinadier J.-P. (Eds.), 2012. To discover and understand Systems Engineering (in french). Cépaduès. ISBN: 978-2364930056.

[5] RobAFIS workspace on the AFIS web site http://www.afis.fr.

[6] RobAFIS dedicated web site: $h$ ttp://www.robafis.fr.

[7] Development repository, downloadable from http://www.robafis.fr

[8] Gouyon, D., Faisandier, A., and Tucoulou, J. C., RobAfis - A Systems Engineering student competition. In $23^{\text {rd }}$ Annual INCOSE International Symposium, Philadelphia, Pennsylvania, USA, June 2013.

[9] Tucoulou J.-C., Auvray G., Systems Engineering Competition, In 24 $4^{\text {th }}$ Annual INCOSE International Symposium, Las Vegas, Nevada, USA, June $25^{\text {th }} 2014$. 